\title{
Heat Capacity of Silver lodide. I. Experiments on Annealed Samples
}

Cite as: J. Chem. Phys. 48, 2143 (1968); https://doi.org/10.1063/1.1669404

Submitted: 07 September 1967 . Published Online: 05 September 2003

C. M. Perrott, and N. H. Fletcher

\section{ARTICLES YOU MAY BE INTERESTED IN}

Heat Capacity of Silver lodide. II. Theory

The Journal of Chemical Physics 48, 2681 (1968); https://doi.org/10.1063/1.1669502

Heat Capacity of Silver Iodide. III. An Order-Disorder Transition

The Journal of Chemical Physics 50, 2770 (1969); https://doi.org/10.1063/1.1671448

Raman Scattering in Wurtzite-Type Agl Crystals

The Journal of Chemical Physics 57, 1215 (1972); https://doi.org/10.1063/1.1678379

Meet the Next Generation of Quantum Analyzers And Join the Launch Event on November 17th

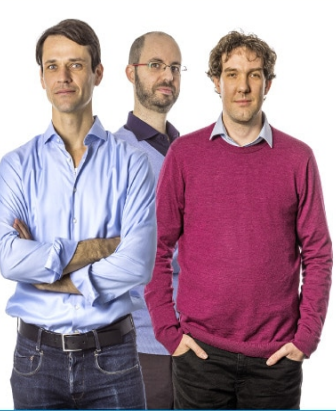

Register now

Zurich - Instruments 


\title{
Heat Capacity of Silver Iodide. I. Experiments on Annealed Samples
}

\author{
C. M. Perrott and N. H. Fletcher \\ Department of Physics, University of New England, Armidale, N.S. W. Australia
}

(Received 7 September 1967)

\begin{abstract}
The heat capacity of silver iodide has been measured over the range $50^{\circ}-400^{\circ} \mathrm{C}$ using an adiabatic calorimeter, the design of which is discussed. Below about $150^{\circ} \mathrm{C}$ the behavior of the $\beta$ form is normal and it transforms to the $\alpha$ form at this temperature with latent heat $1.5 \pm 0.1 \mathrm{kcal} / \mathrm{mole}$. If the sample is stoichiometric, the $\alpha$ form has an anomalously high specific heat $C_{v}$, ranging from $18 \mathrm{cal} / \mathrm{mole} \cdot{ }^{\circ} \mathrm{C}$ at $150^{\circ} \mathrm{C}$ to 26 $\mathrm{cal} / \mathrm{mole} \cdot{ }^{\circ} \mathrm{C}$ at $400^{\circ} \mathrm{C}$. If the sample deviates from stoichiometry by as little as 1 mole $\%$ in either direction, then its specific heat is normal at $12 \mathrm{cal} / \mathrm{mole} \cdot{ }^{\circ} \mathrm{C}$ from $150^{\circ}$ to $400^{\circ} \mathrm{C}$. An interpretation of these results in terms of lattice disorder is suggested.
\end{abstract}

\section{INTRODUCTION}

As part of a program of study of the physical properties of partially disordered solids, we have measured the heat capacity of silver iodide over the range $50^{\circ}-$ $400^{\circ} \mathrm{C}$ by use of an adiabatic calorimeter. In the present paper we report results for annealed samples of pure silver iodide and for samples containing slight excesses of either silver or iodine. Subsequent papers will present a theoretical analysis of this problem and discuss certain nonequilibrium properties of quenched samples.

Silver iodide exists in four solid phases. There is a high-pressure form which has $\mathrm{B} 1(\mathrm{NaCl})$-type structure, and is stable at pressures above $3020 \mathrm{~kg} / \mathrm{cm}^{2},{ }^{1,2}$ The stable form for temperatures below $150^{\circ} \mathrm{C}$ is $\beta$-AgI. It has B4 (wurtzite)-type structure, ${ }^{8}$ in which each silver atom is positioned at the center of a tetrahedron of iodine atoms and vice versa, giving hexagonal symmetry $\left(C_{b_{0}}{ }^{4}\right.$ or $\left.P 6_{3} m c\right)$. There have been reports of another low-temperature form ${ }^{4,5}$ called $\gamma$-AgI. This exists below about $135^{\circ} \mathrm{C}$ and is rather similar in form to $\beta$-AgI, having $\mathrm{B} 3$ (zincblende)-type structure in which the different stacking sequence (ABCABCA $\ldots$ instead of $\mathrm{ABABA} \cdots)$ gives cubic symmetry ${ }^{6}\left(T_{d}{ }^{2}\right.$ or $F \overline{4} 3 m$ ).

Above $150^{\circ} \mathrm{C}$ silver iodide changes, with considerable volume contraction $(5.4 \%)$, to the high-temperature form, $\alpha$-AgI, stable until the melting point. This was first investigated by Strock, ${ }^{7}$ who ascribed the B23-type structure to it. The solid is at least partially ionic in nature, with iodide ions at the points of a body-centered lattice, $(0,0,0)$ and $\left(\frac{1}{2}, \frac{1}{2}, \frac{1}{2}\right)$, while the two silver ions of the unit cell are distributed, with nearly equal probability, over the 42 Wyckoff equipoints of the space

1 G. Tamman, Z. Physik. Chem. 75, 733 (1910).

${ }^{2}$ R. B. Jacobs, Phys. Rev. 51, 999 (1937); 53, 930 (1938) ; 54, 325,468 (1938).

${ }^{3}$ L. Helmholtz, J. Chem. Phys. 3, 740 (1935).

- R. Block and H. Moller, Z. Physik. Chem. A152, 245 (1931).

${ }^{5}$ M. L. Huggins, in Phase Transformations in Solids, R. Smoluchowski, J. E. Mayer, and W. A. Weyl, Eds. (John Wiley \& Sons, Inc., New York, 1951), pp. 238-256.

'N. V. Sidgwick, Chemical Elements and their Compounds (Oxford University Press, New York), Vol. 1, p. 123.

${ }^{7}$ L. W. Strock, Z. Physik. Chem. B25, 441 (1934); B31, 132 (1936). group $0_{h}{ }^{9}$ or $\operatorname{Im} 3 m$ as shown in Fig. 1. The coordinates of these points are obtained by referring the following sets of coordinates to each of the ppints $(0,0,0)$ and $\left(\frac{1}{2}, \frac{1}{2}, \frac{1}{2}\right)$, and then permuting them in cyclic fashion,

$$
\begin{aligned}
6(b): & \left(0, \frac{1}{2}, \frac{1}{2}\right) \frown, \\
12(d): & \left(\frac{1}{4}, 0, \frac{1}{2}\right) \frown,\left(\frac{3}{4}, 0, \frac{1}{2}\right) \frown, \\
24(h): & \left(\frac{1}{2}, \frac{1}{8}, \frac{1}{8}\right) \frown,\left(\frac{1}{2}, \frac{7}{8}, \frac{7}{8}\right) \frown, \\
& \left(\frac{1}{2}, \frac{1}{8}, \frac{7}{8}\right) \frown,\left(\frac{1}{2}, \frac{7}{8}, \frac{1}{8}\right) \frown .
\end{aligned}
$$

The silver ions can move from site to site, with great ease, and give the crystal a large ionic conductivity which is even higher at the melting point than that of the liquid. ${ }^{8}$

This model is further supported by the evidence of Hoshino, ${ }^{2}$ who points out, however, that the $x$-ray data may be equally well explained by assuming other than equal occupation probabilities for the $(b),(d)$, and $(h)$ sites. In the present work, the specific heat of $\alpha$-AgI was measured as a function of temperature in order to determine whether the disorder associated with its unusual structure increases with temperature, thus giving rise to an anomalous specific heat.

\section{THE ADIABATIC CALORIMETER}

In an adiabatic determination of heat capacity, the temperature variation of a system, comprising the sample and its container, is measured as a function of the energy supplied to it. The equation of heat transfer is

$$
\frac{d Q}{d t}=C \frac{d T}{d t}+C^{\prime} \frac{d T}{d t}+\frac{d Q_{L}}{d t},
$$

where $C$ is the heat capacity of the sample, $C^{\prime}$ is the heat capacity of the container, $Q$ is the heat supplied to the system, $Q_{L}$ is the heat lost from the system, $T$ is the absolute temperature of the system, and $t$ represents time. This equation is valid only when the system is

${ }^{8}$ C. Tubandt and E. Lorenz, Z. Physik. Chem. 87, 513, 543 (1914).

${ }^{9}$ S. Hoshino, J. Phys. Soc. Japan 12, 315 (1957). 


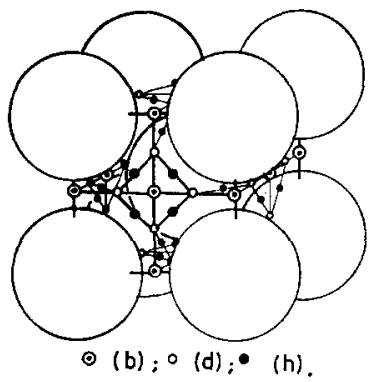

FIG. 1. Schematic drawing of the structure of $\alpha$-AgI (after Hoshino $0^{9}$. The large spheres represent iodide ions and the remaining sites are available to the silver ions.

heated sufficiently slowly to allow the temperature of the interior of the sample, and that of its container, to become uniform.

Determination of heat capacity necessitates separate evaluation of the second and third terms on the righthand side of Eq. (1). In practice, the loss term is made negligible by the design and mode of operation of the calorimeter.

\section{A. Design and Construction}

The adiabatic calorimeter design of Berge and Blanc ${ }^{10}$ was adapted for determination of the heat capacity of silver iodide in the temperature range $50^{\circ}-400^{\circ} \mathrm{C}$. The calorimetric assembly consisted of three metallic vessels, all surfaces of which were polished in order to prevent significant transfer of heat by radiation. It was placed in a high vacuum $\left(\sim 10^{-5}\right.$ torr $)$ so as to eliminate convective heat transfer, and also to prevent deterioration of the polished surfaces at the high temperatures reached.

During experiment, the sample and holder, the design of which will be discussed presently, were heated by an electrical heating plug positioned as shown in Fig. 2. This consisted of a fine nichrome winding on a baked steatite former, radiation losses from the protruding end of the former being prevented by a small copper cap. The electrical leads served to support the whole assembly from the lid of the second cylindrical container, which we will call Can B (Fig. 3).

Can B was constructed from thick copper and completely enclosed the sample holder. Radiation losses through the evacuation outlet in the lid of Can B were prevented by a polished copper reflector positioned below the lid. The electrical heating element was insulated with a mica sheet and situated within a cavity in the wall of the cylinder. Three clamps held the lid in place and also served to create sufficiently good thermal contact that the temperatures of the lid and the body of the can were always closely equal.

The arrangement described above was surrounded by an isolated heat shield. This consisted of a copper can inverted over the calorimeter and supported by a polished copper disk, resting on a silica ring. Chromel/ Alumel thermocouples were positioned on each of the two inner vessels.

${ }^{10}$ P. Berge and G. Blanc, J. Phys. Radium 21, 129A (1960).
The detail of the construction of a suitable sample holder must take account of the following special properties of the substance being examined: (i) poor heat conductivity, (ii) a possible slow rate of establishing phase equilibria, (iii) a tendency to decompose, and (iv) corrosiveness.

The corrosiveness of silver iodide is caused by its tendency to decompose, giving metallic silver and elemental iodine. ${ }^{11}$ However, for a sample in an inert and completely sealed vessel, the iodine rapidly reaches a partial pressure at which the chemical potential of the vapor equals that of the iodine in the solid, and no further decomposition occurs. The equilibrium partial pressure is $l \mathrm{w}^{12,13}$ and the correction to the specific heat is small (see Discussion). The sample holder was therefore required to be completely sealed and corrosion resistant. Grade 303 stainless steel was found to withstand corrosion, even after long periods at $400^{\circ} \mathrm{C}$.

Several sample holders were constructed and the merits of each design analyzed from the respective heating curves obtained with sulfur samples, the mechanical and thermal properties of sulfur being similar to those of AgI. The adopted sample holder (Fig. 2) consisted of a stainless-steel annular cylinder, into which the sample was compacted and the ends sealed by argon arc welding. Contamination of the sample was effectively eliminated by making the welding fins rather long (0.2 in.) and thin (0.006 in.), so that the welding operation was extremely fast. The curves for this design showed (a) the transition temperature for the phase change rombic to monoclinic sulfur to be in the range $92^{\circ}-96^{\circ} \mathrm{C}$, and (b) the melting point of monoclinic sulfur to be within $1^{\circ}$ of $119^{\circ} \mathrm{C} . .^{14}$ The transitions were observed to take place over a temperature interval of less than two Centigrade degrees, and the calculated

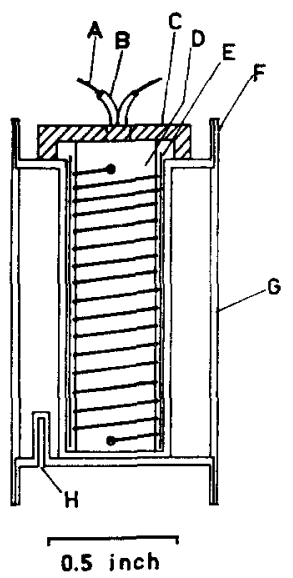

I FIG. 2. The sample holder and heating plug. A, Heating wire; $B$, glass insulating support; C, copper cap; D, steatite former; $\mathrm{E}$, mica sheet; $\mathrm{F}$, welding fins; $\mathrm{G}$, stainless steel (Grade 303 ); $\mathrm{H}$, thermocouple insert

${ }^{11}$ N. H. Fletcher, The Physics of Rainclouds (Cambridge University Press, New York, 1962), pp. 309-310.

${ }_{12}$ K. Jellinek and A. Rudat, Z. Physik. Chem. A143, 55 (1929).

${ }_{13} \mathrm{~K}$. K. Kelley, U.S. Bur. Mines Bull. 383, 132 (1935).

14 Mellor's Modern Inorganic Chemistry, G. R. Parkes, Ed. (Longmans Green and Co., Ltd., London, 1961), p. 470. 
values of the latent heats of transformation ${ }^{15}$ and of fusion ${ }^{16}$ were within $1 \%$ of reported values. Temperature uniformity and phase equilibrium of the sample had therefore been achieved.

\section{B. Operation}

The only means of loss of heat from the sample was by conduction along the two thermocouple wires and the two heater wires. It was not possible to eliminate this, but it was minimized by making the wires as long and as thin as possible. Also, the wires were connected to the lid of Can B in such a way that, although being electrically isolated, they were in good thermal contact with the lid.

The appropriate equation of heat transfer was then

$$
d Q / d t=\left(C+C^{\prime}\right)(d T / d t)+K \delta T,
$$

where $K$ is the coefficient of heat transfer along the wires, and $\delta T$ is the amount by which the absolute temperature of Can A exceeds that of Can B.

The sample was heated with constant power from an experimentally stable power supply and Can B was heated by a power-proportioning temperature controller. This unit was set to maintain the temperature difference $\delta T$, sensed by the opposing emf's of the two thermocouples in the system, at zero. In this way, any temperature variation of the sample was automatically duplicated by its surroundings. Using a chart recorder, the absolute temperature $T$ was measured as a function of time for both the empty sample holder and the filled sample holder. The experimental results were calculated from the equation,

$$
d Q / d T=\left(C+C^{\prime}\right) d T / d t
$$

The over-all performance of the calorimeter was tested with a sodium chloride sample, and the results

Fig. 3. The calorimetric assembly (schematic drawing). This assembly is placed in a chamber evacuated to $\sim 10^{-5}$ torr. $A$, Copper heat shield; B, copper can and lid; C, clamp; D, reflector; $\mathrm{E}$, thermocouple; $\mathrm{F}$, sample holder; $G$, glass beads; $H$, electrical lead; I, silica ring; $J$, glass metal lead throughs; $\mathbf{K}$, heating ribbon; L, mica sheet.

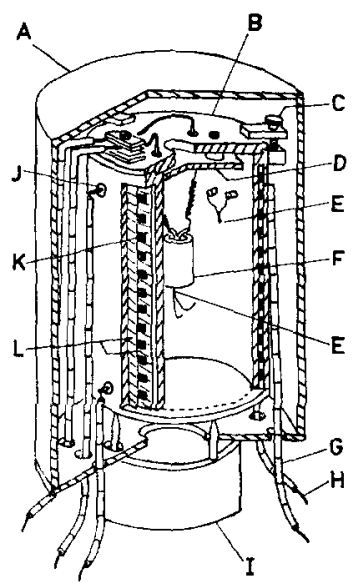

${ }^{15}$ International Critical Tables (McGraw-Hill Book Co., New York, 1930), Vol. 7, p. 236.

${ }_{16}$ Reference 15, Vol. 5, p. 131.

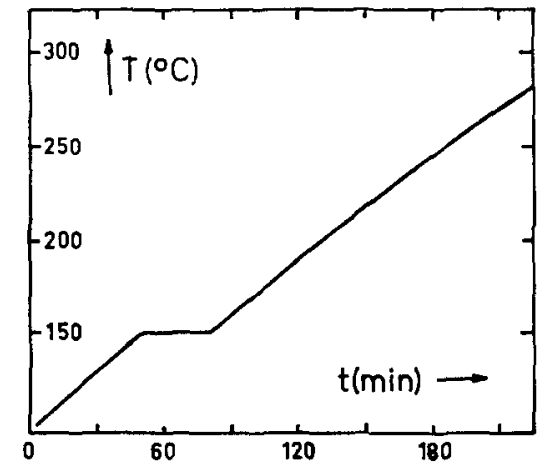

FIG. 4. A typical heating curve for pure silver iodide, showing the phase transition $\beta$-AgI to $\alpha-\mathrm{AgI}$ at $150^{\circ} \mathrm{C}$.

obtained were within $2 \%$ of reported values ${ }^{17,18}$ over the temperature range $40^{\circ}-200^{\circ} \mathrm{C}$.

\section{EXPERIMENTAL}

\section{A. Preparation of Sample}

The silver iodide was precipitated from an aqueous solution of potassium iodide by a slight excess of aqueous silver nitrate solution. The precipitate was flocculated and washed in a filtering crucible with deionized distilled water. Completeness of washing was tested by determining whether the excess of the precipitating agent (silver nitrate) had been removed-the washings become turbid on addition of hydrochloric acid if silver ions are present. The crucible and contents were dried in an air oven at $90^{\circ} \mathrm{C}$ for $5 \mathrm{~h}$, cooled in a desiccator, and weighed. Heating was repeated for periods of $1 \mathrm{~h}$, until constant weight was attained.

Using a stainless-steel ram, the dried powder was compacted in to the sample holder, and the ends sealed by argon arc welding. A sample density of $5.30 \mathrm{~g} / \mathrm{cc}$ at room temperature was achieved-the single-crystal density of silver iodide at $20^{\circ} \mathrm{C}$ is $5.67 \mathrm{~g} / \mathrm{cc}^{19}$ The sample itself comprised 0.1 mole.

\section{B. Latent Heat of Transformation}

A typical heating curve for silver iodide is shown in Fig. 4. The endothermic phase transition $\beta$-AgI to $\alpha$-AgI at about $150^{\circ} \mathrm{C}$ is clearly shown by the abrupt fall of the heating rate at that temperature. The average time taken for the sample to undergo the transition was determined from a number of heating curves, each being applicable to the same constant rate of heat input to the sample, and the latent heat of transformation calculated to be

$$
\delta Q=1.5 \pm 0.1 \mathrm{kcal} / \mathrm{mole} .
$$

The entropy change at the transition is then

$$
\delta S=3.5 \pm 0.3 \mathrm{cal} / \mathrm{mole} \cdot{ }^{\circ} \mathrm{C} \text {. }
$$

${ }_{17}$ Reference 15 , Vol. 5, p. 90.

18 L. Hunter and S. Siegel, Phys. Rev. 61, 90 (1942).

${ }^{19}$ Reference 15, Vol. 1, p. 124. 


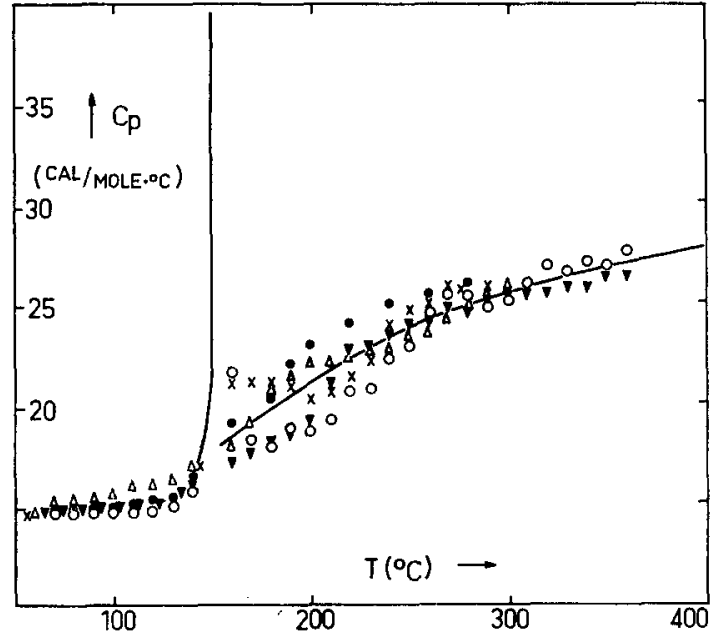

FIG. 5. Molar heat capacity of annealed samples of stoichiometric silver iodide. $\triangle$, Sample annealed at $350^{\circ} \mathrm{C}$; samples annealed after quenching from $\times, 400^{\circ} \mathrm{C} ; 0,350^{\circ} \mathrm{C} ; \mathrm{O}, 300^{\circ} \mathrm{C}$; $\nabla, 250^{\circ} \mathrm{C}$.

Reported values of these quantities are compared in Table I.

\section{Molar Heat Capacity at Constant Pressure}

The molar heat capacity of annealed silver iodide samples was determined as a function of temperature, and is shown in Fig. 5. Because the specific heat becomes very large at the transition, it is not possible to obtain an accurate value of the latent heat by estimating the area between the peak and an interpolation of the curve below the transition. In fact, this procedure gives a latent heat of less than $100 \mathrm{cal} / \mathrm{mole}$ (Nolting ${ }^{20}$ also draws attention to this difficulty).

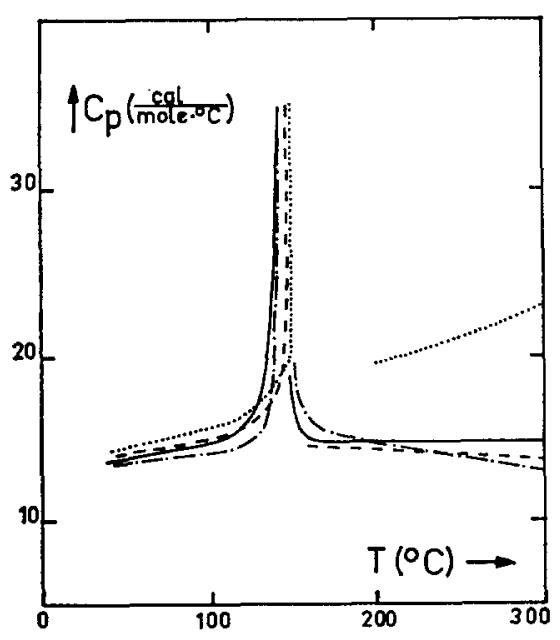

FIG. 6. Reported variations of the molar heat capacity of AgI. $\cdots$, Lieser $^{21}$; -.•, Hoshino $0^{9}---$, Jost et al. ${ }^{22}$; -

${ }^{20} \mathrm{~J}$. Nolting, Ber. Bunsenges. Physik. Chem. 67, 172 (1963).
Previously reported values of the specific heat are compared in Fig. 6. The present result seems to be in agreement with that of Lieser, ${ }^{21}$ while those of Hoshino, ${ }^{9}$ Jost et al. ${ }^{22}$ and Nolting ${ }^{20}$ are themselves in good agreement. A further investigation was then made with a view to determining the reason for these variations.

Summarizing the respective experiments, we see that

(i) The present work was done with a pure AgI compact enclosed in a stainless-steel vessel.

(ii) Lieser's experiment was conducted in a freely suspended platinum crucible under high vacuum.

(iii) Hoshino used a sample sealed into a "hardglass" vessel.

(iv) Jost $e t$ al. and Nolting used essentially identical calorimeters in which the sample was fused in a silverlined container, which was also stocked with free silver.

Tests having shown that metallic silver is definitely not inert to $\alpha$-AgI, samples were prepared which contained amounts of metallic silver in excess of that required for stoichiometric silver iodide. The silver was introduced as small pieces of fine silver wire distributed through the AgI compact. This was sealed into the

TABLE I. Latent heat and entropy change for the phase transition of $\mathrm{AgI}$ at $150^{\circ} \mathrm{C}$.

\begin{tabular}{ccl}
\hline $\begin{array}{c}\delta Q \\
(\mathrm{kcal} / \mathrm{mole})\end{array}$ & $\begin{array}{c}\delta S \\
\left(\mathrm{cal} / \mathrm{mole} \cdot{ }^{\circ} \mathrm{C}\right)\end{array}$ & References \\
\hline 1.50 & 3.5 & Lieser $^{21}$ \\
1.53 & 3.6 & Hoshino $^{9}$ \\
2.04 & 4.8 & Jost et al. $^{22}$ \\
1.415 & 3.4 & Nolting $^{20}$ \\
\hline
\end{tabular}

sample holder and then held at temperatures between $400^{\circ}$ and $500^{\circ} \mathrm{C}$ for several hours, in order that diffusion of the silver should give rise to a fine uniform distribution of silver in equilibrium with $\alpha$-AgI at the annealing temperature, and so facilitate the attainment of equilibrium at all lower temperatures.

The specific heat of silver iodide in equilibrium with metallic silver was determined (Fig. 7) and found to agree well with the curves of Hoshino, Jost et al., and Nolting. Note the lack of dependence of specific heat on excess silver concentration for silver-rich $\alpha$-AgI. Within the experimental error, no change in the latent heat, as a result of silver impurity, was observed.

Because small amounts of silver caused such a marked shift in the specific heat of $\alpha$-AgI, the effects of excess iodine were also investigated (Fig. 7). In this case, uniform distribution of iodine was attained by heating a sealed sample holder, containing the doped compact, to a temperature above the boiling point of iodine-

${ }^{21}$ K. H. Lieser, Z. Physik. Chem. (Frankfurt) 2, 238 (1954). ${ }_{22}$ W. Jost, H. J. Oel, and G. Schniedermann, Z. Physik. Chem. (Frankfurt) 17, 175 (1958). 
usually $200^{\circ} \mathrm{C}$. After several hours at this temperature, the samples were heated to $400^{\circ} \mathrm{C}$ and held there for a few hours, in order that equilibrium should be assured throughout the measuring range. As for the silver-doped samples, no change in the latent heat of transformation $\beta$-AgI to $\alpha$-AgI was observed.

\section{DISCUSSION}

Before accepting these results we must establish that they represent true equilibrium behavior and do not have any simple explanation in terms of the chemical reactivity of silver iodide. The existence of equilibrium was established by the fact that repeated measuring runs with the same sample and with different pure samples gave essentially identical results, while this was also true of doped samples. The possibility of reversible chemical reaction requires more detailed discussion.

\section{A. Evolution of Iodine by a Pure Sample}

Silver iodide melts at $555^{\circ} \mathrm{C}^{20}$ and decomposition also occurs at about this temperature..$^{23}$ At all temperatures, there will then be a partial pressure of iodine above solid silver iodide, and the equilibrium value of the pressure will increase with temperature. For a given sample, therefore, iodine will be evolved at an increasing rate as the temperature is raised.

Experimentally, the fractional free volume of the container at $500^{\circ} \mathrm{C}$ was $21.64 \mathrm{cc} /$ mole of sample. The vapor pressure above AgI has been quoted as less than $1 \mathrm{~mm} \mathrm{Hg}$ at $500^{\circ} \mathrm{C},{ }^{16}$ but there is some uncertainty about the physical conditions of this measurement. Even if we assume an iodine pressure as high as 100

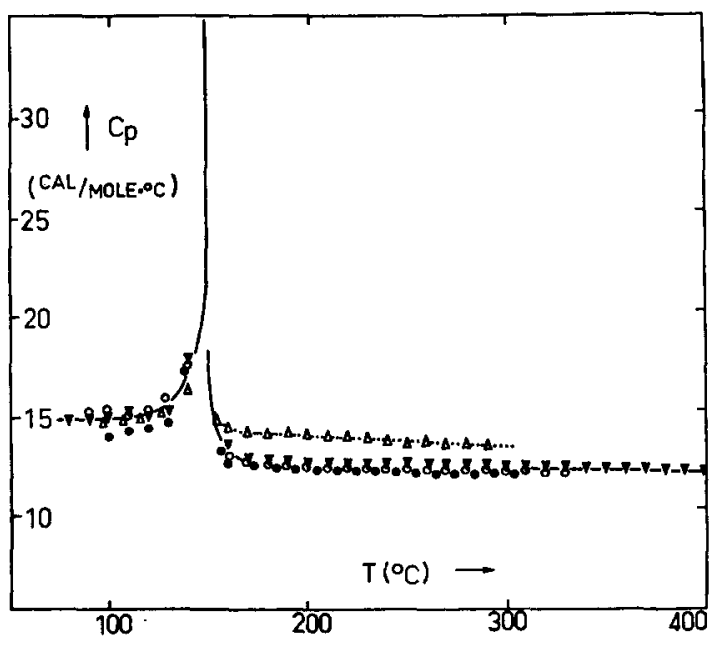

FIG. 7. Molar heat capacity of nonstoichiometric silver iodide. 2.65 mole $\%$ excess silver (annealed at $400^{\circ} \mathrm{C}$ );, 0.95 mole $\%$ excess silver $\left(450^{\circ} \mathrm{C}\right) ; 0,0.68$ mole $\%$ excess silver $\left(500^{\circ} \mathrm{C}\right)$ $\triangle, 0.85$ mole $\%$ excess iodine $\left(400^{\circ} \mathrm{C}\right)$.

${ }^{23}$ N. H. Fletcher, Ref. 11, p. 311.

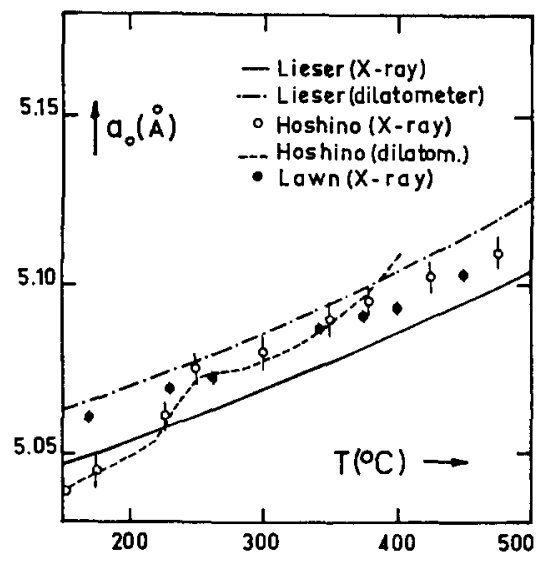

FIG. 8. Reported variations of the lattice constant of $\alpha$-AgI.

$\mathrm{mm} \mathrm{Hg}$ at this temperature, we find that less than 1 in $10^{4}$ parts of the sample have been decomposed.

Now, the heat of formation of $\mathrm{AgI}$ from silver and solid iodine at $20^{\circ} \mathrm{C}$ is $14.93 \mathrm{kcal} / \mathrm{mole},{ }^{24}$ the latent heat of sublimation of iodine is $10.06 \mathrm{kcal} / \mathrm{mole},{ }^{25}$ and the latent heat of transformation of $\beta-\mathrm{AgI}$ to $\alpha$ - $\mathrm{AgI}$ is $1.5 \mathrm{kcal} / \mathrm{mole}$ (above). The heat of formation of $\alpha-\mathrm{AgI}$ from silver and diatomic iodine gas is thus expected to be approximately $18 \mathrm{kcal} / \mathrm{mole}$.

The heat energy required to partially decompose the silver iodide has the effect of raising the observed heat capacity above its true value. Assuming a vapor pressure of $100 \mathrm{~mm} \mathrm{Hg}$ at $500^{\circ} \mathrm{C}$, we find that the quantity of heat involved is $1.6 \mathrm{cal} / \mathrm{mole}$ of sample. This represents an average displacement of the molar heat capacity of $\alpha$-AgI by only $0.005 \mathrm{cal} / \mathrm{mole} \cdot{ }^{\circ} \mathrm{C}$. In order to obtain a significant correction because of this process, we would have to assume equilibrium partial pressures of the order of tens of atmospheres.

\section{B. The Effect of Silver on the Heat Capacity of $\alpha$-AgI}

Since the structure of $\alpha$-AgI is statistical to the extent that two silver atoms occupy, with equal probability, 42 sites in the lattice, it seems feasible that small amounts of excess silver may enter the lattice by means of a reaction which is to a first approximation one between a free atom of silver and an atom of iodine in the lattice, only the state of the silver being changed.

The heat of formation mentioned above pertains to the formation of $\alpha$-AgI from silver and gaseous iodine. In such a reaction, energy of $36.1 \mathrm{kcal} / \mathrm{mole}$ of iodine is expended in breaking the I-I bonds ${ }^{26}$ of the diatomic gas. We shall therefore assume that the heat of reaction for the process in question is the standard heat of formation of $\alpha$-AgI, plus the dissociation energy of the corresponding amount of iodine, that is, $36 \mathrm{kcal} / \mathrm{mole}$ of $\alpha$-AgI formed or per mole of silver absorbed.

\footnotetext{
${ }^{24}$ Reference 15, Vol. 5, p. 188.

${ }^{25}$ Reference 15, Vol. 5, p. 135; Vol. 1, p. 104.

${ }^{26} \mathrm{~L}$. Pauling, The Nature of the Chemical Bond (Cornell University Press, Ithaca, N.Y. 1960), 3rd ed., pp. 83-85.
} 
TABLE II. Correction $C_{p}-C_{v}$ for $\alpha$-AgI at various temperatures.

\begin{tabular}{cccccccccccc}
\hline$T\left({ }^{\circ} \mathrm{C}\right)$ & 160 & 175 & 200 & 225 & 250 & 275 & 300 & 325 & 350 & 400 & 1.42 \\
\hline$C_{p}-C_{v}\left(\mathrm{cal} / \mathrm{mole} \cdot{ }^{\circ} \mathrm{C}\right)$ & 0.80 & 0.85 & 0.92 & 1.04 & 1.12 & 1.22 & 1.32 & 1.42 & 1.56 & 1.76 & \\
\hline
\end{tabular}

The experiments have shown that the shift in heat capacity of $\alpha-\mathrm{AgI}$ is the same for samples containing $0.68,0.95$, and 2.65 mole $\%$ excess silver. This does not necessarily mean that the effect is independent of the total amount of excess silver in the lattice. It seems feasible that the silver enters the lattice reversibly by a reaction of the type discussed immediately above. In this process, silver is absorbed by the $\alpha$-AgI at an increasing rate as the sample is heated. On cooling, the sample rejects this silver which then becomes colloidally dispersed throughout the sample. The amount of extra silver in the lattice is determined only by the temperature.

Let us now consider the experimental samples. Since the effect is the same for all three silver concentrations, we must conclude that the total amount of silver absorbed between $150^{\circ}$ and $350^{\circ} \mathrm{C}$ is less than that contained in the sample with 0.68 mole \% excess silver. The energy liberated when a mole of $\alpha$-AgI absorbs this amount of silver is, according to our above assumptions, found to be $245 \mathrm{cal}$. Even assuming all the silver to be expended at $350^{\circ} \mathrm{C}$, we see that the average depression of the molar heat capacity, due to evolved heat of reaction, is $1.2 \mathrm{cal} / \mathrm{mole} \cdot{ }^{\circ} \mathrm{C}$ between $150^{\circ}$ and $350^{\circ} \mathrm{C}$. Comparing the curves of Figs. 5 and 7, we see that this process cannot account for the observed difference.

Obviously, the analogous explanation for the case of excess iodine also fails. It is appropriate to remark here that the pressure above iodine-doped samples is extremely low even at temperatures above the boiling point of iodine. This indicates that the process of combination between iodine and $\alpha$ - AgI is essentially completed within the range $150^{\circ}-180^{\circ} \mathrm{C}$.

\section{Specific Heat at Constant Volume for $\alpha$-AgI}

Before attempting to interpret the observed specific heat, we must convert the values from specific heat at constant pressure, $C_{p}$, to specific heat at constant volume, $C_{v}$. It may be shown that ${ }^{27}$

$$
C_{v}=C_{p}-T V_{m}\left(9 \alpha t^{2} / K\right),
$$

where $T$ is absolute temperature, $V_{m}$ is molar volume, $\alpha_{l}=\left(a_{0}\right)^{-1}\left(\partial a_{0} / \partial T\right)$ is the coefficient of linear expansion, and $K=V^{-1}(\partial V / \partial P)_{T}$ is the compressibility.

27 F. Seitz, The Modern Theory of Solids (McGraw-Hill Book Co., New York, 1940), p. 137.
We therefore need to know the values of $V_{m}, \alpha_{l}$, and $K$ as a function of temperature. The first two may be obtained from the temperature variation of the lattice parameter $a_{0}$, which has been measured ${ }^{9,28-30}$ (see Fig. 8 ). The values of $\alpha_{l}$ calculated from Hoshino's results fluctuate considerably, in contrast with the smooth behavior reported by Lieser, Majumdar and Roy, and Lawn. They were therefore disregarded in the evaluation of Eq. (4) though we shall see later that they are significant in interpretation of the behavior of quenched samples. In the absence of data on the compressibility of $\alpha$-AgI, it was found necessary to use the value $K=4.11 \times 10^{-12} \mathrm{~cm}^{2} /$ dyn which applies to $\beta$-AgI at $40^{\circ} \mathrm{C}^{31}$

The values of $C_{p}-C_{v}$ thus calculated are given in Table II and, though significant, are seen not to affect the general pattern of behavior seen in Figs. 5 and 7.

\section{CONCLUSION}

From the experimental results and subsequent discussion we conclude that the heat capacity at constant volume of stoichiometric $\alpha-\mathrm{AgI}$ is genuinely anomalous, rising from 18 to $26 \mathrm{cal} / \mathrm{mole} \cdot{ }^{\circ} \mathrm{C}$ at $400^{\circ} \mathrm{C}$. On the other hand, samples which are nonstoichiometric to the extent of as little as 1 mole $\%$ in either direction show a normal heat capacity of about $12 \mathrm{cal} / \mathrm{mole} \cdot{ }^{\circ} \mathrm{C}$.

It is tempting to explain these results in terms of a temperature-dependent disorder in the case of pure samples and to assume that in nonstoichiometric material the disorder is essentially fully developed at the $150^{\circ} \mathrm{C}$ phase transition. A detailed theoretical analysis along these lines is presented in Paper II of this series.

\section{ACKNOWLEDGMENTS}

The authors wish to acknowledge the help of Dr. W. D. Scott and Mr. C. K. Lim who did some preliminary work on the calorimeter design. They are also grateful to the Australian Commonwealth Scientific and Industrial Research Organization and the Australian Commonwealth Research Grants Committee for financial support. One of us (C.M.P.) also wishes to thank the C.S.I.R.O. for a Postgraduate Scholarship during the tenure of which this work was done.

\footnotetext{
${ }^{28}$ K. H. Lieser, Z. Physik. Chem. (Frankfurt) 5, 125 (1955). ${ }^{29}$ B. R. Lawn, Acta Cryst. 17, 1341 (1964).

30 A. J. Majumdar and R. Roy, J. Phys. Chem. 63, 1858 (1959).

31 Reference 15, Vol. 3, p. 50.
} 